Der Arzt und sein Steuerberater

\section{Sind Sie in guten Händen?}

\author{
Die Honorarabrechnung des Steuerberaters ist für den Arzt häufig ein Ärgernis. \\ Der Eindruck, zu viel Geld für zu wenig Leistung zu bezahlen, verursacht den \\ Kollegen Bauchschmerzen. Die KV Westfalen-Lippe rät: Nehmen Sie die Kosten \\ für den Steuerberater ruhig mal unter die Lupe und stellen Sie Vergleiche an. \\ Außerdem gibt die KV Tipps, was ein guter Steuerberater leisten sollte.
}

— Die Gebühren für den Steuerberater können erheblich schwanken, denn auch dieser Berufsgruppe ist es erlaubt, den Schwierigkeitsgrad ihrer Arbeit zu bewerten bzw. bei aufwendigeren Arbeiten einen höheren Satz zu verlangen. Bei den Buchführungskosten beispielsweise bewegt sich die Spannweite von 2/10 bis 12/10 der Gebühr. Das heißt, der eine Arzt (der möglicherweise seine Quittungen im Schuhkarton abgibt) muss 600 Euro an den Steuerberater bezahlen, der andere (gut organisierte) Arzt hingegen nur 100 Euro. Dies hängt aber nicht nur von der Einschätzung des Steuerberaters ab, sondern durchaus auch vom Verhandlungsgeschick des Arztes.

\section{Ärzte sind eher unkompliziert}

Bei Ärzten jedenfalls, meint die KV Westfalen-Lippe, sind Buchhaltung und Steuererklärung in der Regel recht einfache und unkomplizierte Vorgänge. Deshalb müssten die Gebühren hier eher im unteren Bereich angesiedelt sein. Tatsächlich lägen die Kosten aber fast immer im oberen Mittelfeld.

Natürlich hängt die Bewertung eines Steuerberaters auch davon ab, wie gut er berät und ob er dem Arzt auch kontinuierlich aktuelle Auswertungen und Daten zukommen lässt. Um ein Gespür dafür zu entwickeln, bietet sich ein Ge-

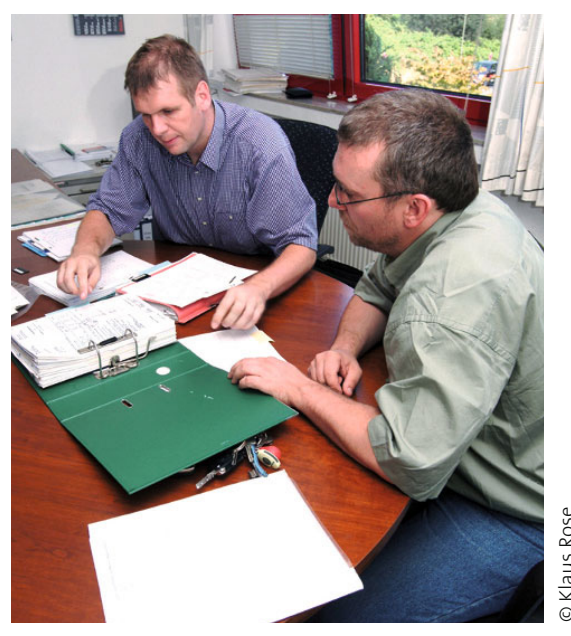

Ein guter Steuerberater unterstützt den Arzt beim alltäglichen Papierkrieg.

spräch mit vertrauten Kollegen an. Welchen Service leistet der Steuerberater des/der anderen? Wie hoch belaufen sich in etwa deren Kosten? Wie gut bereitet sich der Kollege dabei vor? Als weitere Möglichkeit mag ein Anruf bei zwei bis drei Steuerberatern mit der Bitte um ein Angebot hilfreich sein. Hier gilt es abzufragen, was im Honorar enthalten ist und was zusätzlich angesetzt wird (telefonische Beratung, Fahrtkosten, Beratungszeit vor Ort etc.).

Gut ist in der Regel, wenn der Steuerberater sich zumindest ansatzweise mit den spezifischen Gegebenheiten des Arztes auskennt.
Fragen, die Sie stellen sollten

Um die Qualität der Beratung ein wenig besser abschätzen zu können, rät die KV Westfalen-Lippe zur Beantwortung folgender Fragen:

- Ist eine gewisse Sympathie vorhanden? Kann ein Vertrauensverhältnis aufgebaut werden?

- Ist der Steuerberater leicht erreichbar (Handy-Nr.)?

- Liegt die betriebswirtschaftliche Auswertung spätestens am Ende des nächsten Monats vor?

- Wird ein arztspezifischer Kontenrahmen verwendet (SKR81)?

- Sind die Auswertungen verständlich und nachvollziehbar?

- Sind die wesentlichen Zahlen der Praxis zusätzlich auf einer Seite zusammengefasst?

- Enthält die Auswertung einen internen Vergleich? Sind Veränderungen zum Vorjahr, Vorquartal, Vormonat ersichtlich?

- Ist eine Entwicklung der eigenen Praxis im Vergleich zu Kollegen gleicher Fachgruppe und Umsatzklasse enthalten?

- Werden regelmäßige Liquiditäts- und Rentabilitätsberechnungen durchgeführt und diese mit Ihnen mindestens halbjährlich besprochen?

- Erhalten Sie unaufgefordert und regelmäßig Informationen, welche Summen Sie für Steuernach- und -vorauszahlungen zur Seite legen müssen?

Wenn obige Fragen alle mit "Ja" beantwortet werden können, ist der Arzt bei seinem Steuerberater gewiss in guten Händen. Eine vergleichsweise höhere Honorarforderung wäre dann begründet.

ANKe THOMAS :

- Quelle: Praxismanagement-Tipps der KV Westfalen-Lippe unter www.kvwl.de, hier: Rubrik „KV Dienste“ 